\title{
Women in mining still exploited and sexually harassed
}

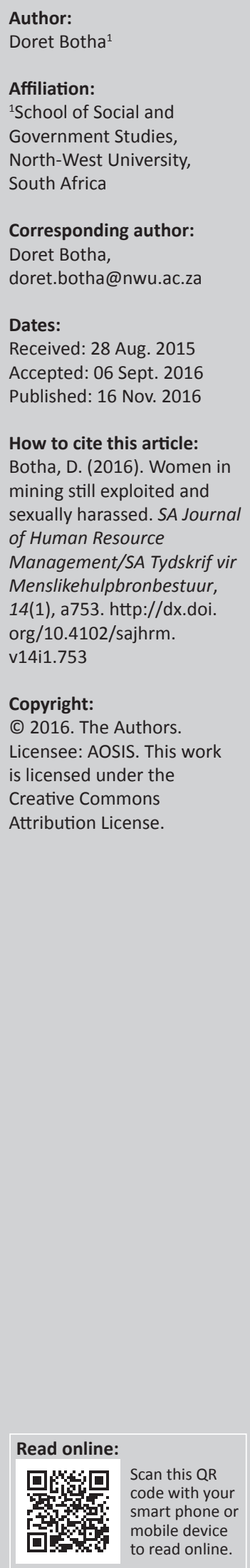

Orientation: Globally, women have become an essential part of the mining workforce. Among other jobs, they fulfil management positions, operate heavy machinery and are involved in artisanal mining processes. In South Africa, new mining legislation not only prohibits the exclusion of women but requires from companies to actively change the demographic profile of their workforce. Mining companies are obliged to also employ women in core mining activities. Although well intended, women appointed in core positions work side by side with men, often in isolation, and are frequently at risk of sexual abuse and/or harassment.

Research purpose: This research determined perceptions regarding the occurrence of sexual harassment among women working in core mining positions.

Motivation for the study: Currently, there is a paucity of published data on the occurrence of sexual harassment in the mining industry.

Method: A mixed-method research design was used including quantitative and qualitative research paradigms. Quantitative data were collected by means of a structured questionnaire. Qualitative data were collected by means of individual and group interviews.

Main findings: From the literature review and the empirical findings, it is evident that women are still exploited and sexually harassed in the mining industry. Incidents taking place on a daily basis vary from whistling; name calling; use of vulgar or derogatory language; display of body parts; physical contact, ranging from touching to sexual assault and rape; to the exchange of sexual favours for promotion.

Practical/managerial implications: It is evident from the research that a holistic approach is required to effectively eradicate sexual harassment in the mining industry, involving the commitment of relevant state departments, human resource managers and labour experts.

Contribution: Practical recommendations are made to effectively address sexual harassment in the mining industry.

\section{Introduction}

Although few in numbers, women have now globally become an essential part of the mining workforce, mainly because of equal opportunity legislation, which obliged mining companies to actively change the demographic profile of their workforce. Currently, women miners play various roles in mining; they fulfil management positions, operate heavy machinery and are involved in artisanal mining processes, among others.

In South Africa, the newly elected democratic government of 1994 adopted a number of strategies to open up the mining sector to historically disadvantaged South Africans, which include women, as part of its economic empowerment policy. Among others, new mining legislation, such as the Mineral and Petroleum Resources Development Act (No. 28 of 2002) (Republic of South Africa [RSA], 2002) and the Broad-based Socio-economic Empowerment Charter for the South African Mining Industry (the Mining Charter) (RSA, 2004), was introduced. These pieces of legislation not only prohibit the exclusion of women but also require from companies to actively change the demographic profile of their workforce by setting specific targets to be reached by 2015. Core mining activities refer to positions in mining that include, among other activities, mining, metallurgy, engineering and geology (Harmony Gold Mining Company, 2008).

Although well intended, women working in the male-dominated mining environment are facing a range of obstacles, including sexual harassment (Badenhorst, 2009; Fourie, 2009; Managing Transformation Solutions [MTS], 2011; Women in Mining Canada, 2010). Women appointed in core positions work side by side with men, often in isolation, and are frequently at risk of sexual abuse and/or harassment. Employees working underground in the mine are in very close 
proximity to one another while being transported from the surface to the workplace underground, which also increases the risk of sexual harassment. Furthermore, male colleagues often refuse to provide the necessary support to their new female colleagues, in other words, the informal job induction process, camaraderie and cooperative teamwork that they need to succeed. Instead, they regularly ignore, harass and undermine their new female colleagues (Hakim, 2004). Gender discrimination and sexual harassment could affect women's psychological health, generating stress-related reactions such as emotional trauma, anxiety, depression, anger and low self-esteem and also affect their physical health, causing stress-related diseases such as sleep disorders, headaches, stomach problems and ulcers (Mining Safety, 2013).

In light of the above background, the problem statement can be outlined as follows: On the one hand, mining companies are obliged to reach the set targets of the Mining Charter. Failing to adhere to the requirements of the Charter could result in mining companies losing their licences to operate. On the other hand, the requirement of the Mining Charter to include more women in the core business of mining broadened employment opportunities for women and therefore contributes to decreasing poverty in South Africa. However, at the same time, women are exposed to various challenges and risks, including sexual harassment.

\section{Purpose}

Based on the problem statement described above, the purpose of the article is, firstly, to operationalise and conceptualise sexual harassment according to the literature; secondly, to provide theoretical explanations for the occurrence of sexual harassment in the mining industry; thirdly, to explore the occurrence of sexual harassment among women in mining according to the literature; fourthly, to determine sexual harassment issues among women in mining at selected mines; and lastly, to provide some recommendations to address sexual harassment in the mining industry.

\section{Literature review}

\section{Sexual harassment operationalised and conceptualised}

According to Pons and Deale (2010) sexual harassment is regarded as 'unwanted conduct of a sexual nature' and may include 'unwelcome physical, verbal or non-verbal conduct'. Physical conduct of a sexual nature refers to all unwanted physical contact, for example, brushing up against a person, touching a person, forced fondling (Grobler, Wärnich, Carrel, Elbert and Hatfield, 2011) and may also include sexual assault and rape (Pons \& Deale, 2010). Verbal forms of sexual harassment include, among others, unwelcome innuendoes, suggestions and hints, comments with sexual overtones (Pons \& Deale, 2010), sexual stories or jokes, whistling and repeatedly asking someone out (Grobler et al., 2011). Non-verbal forms of sexual harassment refers to unwelcome gestures, including staring at someone, sending email messages of a sexual nature (Grobler et al., 2011) and the unwelcome display of sexually explicit pictures and objects (Pons \& Deale, 2010).

Quid pro quo harassment relates to a situasion where a victim is coerced into acceding to the advances of a superior (employer, supervisor or manager) or co-employee in exchange for work-related benefits (such as promotion, training, discipline, dismissal or salary increment) (Grobler et al. 2011; Pons \& Deale, 2010). Sexual favouritism refers to a situasion where a superior rewards only those who respond to his or her sexual advances, while other deserving employees who do not submit themselves to any sexual advances are denied promotions, merit rating or salary increases (Pons \& Deale, 2010).

Sexual harassment can be seen as an abuse of power by which perpetrators use their position to exploit subordinates. Sexual harassment occurs in every kind of work setting, but some settings are more prone to sexual harassment than others (Wharton, 2006). A strong predictor of sexual harassment is a work setting with a high male-to-female ratio. Therefore, women working in a male-dominated workplace, for example, mining, are particularly vulnerable to sexual harassment (Haralambos \& Holborn, 2008; Martin, cited in Anderson \& Taylor, 2006; Wharton, 2006).

Although both women and men can be victims of sexual harassment, research suggests that women are more likely to experience sexual harassment than men (Wharton, 2006). According to Anderson and Taylor (2006), most surveys indicate that as many as half of all employed women experience some form of sexual harassment at some time. The authors further assert that there is evidence that women of colour are more likely to be harassed than white women. Furthermore, the authors argue that men tend to see sexual harassment as normal and tolerable and do not think of harassment as doing something wrong. Women, on the other hand, tend to see harassment as inappropriate behaviour and judge it more severely than men.

Sexual harassment also appears to be underreported. Studies revealed that employees - women as well as men - are unaware of proper channels to report these issues. Women are also less likely to report these incidents because they believe nothing will be done to stop the behaviour (Anderson \& Taylor, 2006). A national study undertaken in the United States found that only $5 \%$ of women and men who had experienced sexual harassment chose to report it. Grobler et al. (2011) cite the primary reasons why the other 95\% did not report these incidents as the following: the fear of losing their job, the need for a future job reference, the possibility of being considered a troublemaker, the assumption that nothing would change if the harassment was reported, concern about being accused of inviting the harassment, reluctance to draw public attention to their private lives and the prospect of emotional stress for filing a lawsuit and undergoing long, costly legal procedures. 
The consequences of sexual harassment can be economic, emotional and physical. By creating a hostile working environment, sexual harassment can influence productivity at work. Workers who have been sexually harassed may experience feelings of helplessness, fearfulness and powerless. Victims also tend to lose their ambition and selfconfidence and experience a negative attitude towards their work (Anderson \& Taylor, 2006).

\section{Theoretical explanations for the occurrence of sexual harassment}

Because of the contemporary women's rights movement that began in the late 1960s, much has changed for both women and men in societies globally. However, despite tremendous advancements for women since the 1960s, gender inequality persists and manifests itself in many ways, among others in various discriminative practices, such as sexual harassment (Barkan, 2012).

A number of theoretical perspectives aimed to provide explanations for the occurrence of sexual harassment in the workplace. The following theoretical perspectives are presented: the natural/biological theory, socio-cultural theory, organisational theory, sex-role spillover theory, the four-factor theory of sexual harassment and feminist perspectives.

The natural/biological theory suggests that sexual harassment is not actually harassment and does not have harmful consequences (McDonald, 2012). Sexual advances are not seen as unacceptable behaviour, but rather as a portrayal of the other individual's true feelings (Slabbert, 1994). According to this theory, sexual harassment occurs as a result of the natural attraction between men and women. The theory suggests that because of men's strong sex drive, they behave in a sexually aggressive manner, also in the workplace (O'Hare \& O'Donohue, 1998). This theory is limited in its application for the following reasons: It assumes that sexual and gender discrimination does not exist in the workplace; it does not consider the effects of harassment on an individual or his or her organisation and therefore it does not recognise the need for procedures to deal with it (Joubert, 2009).

Socio-cultural theories are mainly feminist in orientation. They investigate the wider social and political context in which sexual harassment is created and occurs (Pina, Gannon \& Saunders, 2009). The socio-cultural theory posits that sexual harassment reflects the larger society's differential distribution of power and status between the sexes (Tangri, Burt \& Johnson, 1982). Sexual harassment is also seen as a mechanism that functions to maintain male dominance over women within the economy and specifically the workplace (Tangri et al., 1982). The socio-cultural theory also maintains that men and women are socialised in such a way that this structure of dominance and subordination is maintained (O’Hare \& O'Donohue, 1998). Men are socialised to be more aggressive and assertive and women to be passive and sexually attractive and to avoid conflict (Tangri et al., 1982). This theory fails to explain the harassment of men by women or harassment of workers from the same gender who are supposed to be similar products of socialisation (Joubert, 2009).

According to the organisational theory, sexual harassment in the workplace occurs because of power differentials created by hierarchical structures of organisations (Tangri et al., 1982). Superiors in legitimate positions use their power to intimidate and control their subordinates for their own sexual gratification (O'Hare \& O'Donohue, 1998). A key strength of the organisational theory is that a number of organisational factors are identified to explain the sexual harassment phenomenon (Pina et al., 2009). The following organisational characteristics are viewed as contributing factors to the incidence of sexual harassment: contact with the opposite sex on the job, the ratio of men to women in the workplace, occupational norms, job functions, job alternatives and availability of grievance procedures (O'Hare \& O'Donohue, 1998). However, this theory does not consider people's individual differences and how their everyday behaviour, stereotypes and expectations can influence the occurrence of the phenomenon (Pina et al., 2009).

The sex-role spillover theory argues that sexual harassment occurs because of the carryover of gender-based expectations into the workplace that are irrelevant to, and inappropriate for, work (O'Hare \& O'Donohue, 1998). Therefore, sexual harassment tends to occur in work environments where the sex ratio is skewed in either direction. Women's sex role becomes more prominent when working in male-dominated or female-dominated occupations, thereby facilitating sexual harassment. In male-dominated occupations, women's gender is noticeable because of their singularity and distinctiveness. In female-dominated occupations, women's sex role is emphasised, for example, the helper role of administrative assistants, resulting in the job itself acquiring aspects of the sex role (O'Hare \& O'Donohue, 1998). Although this theory combines aspects of the organisational and socio-cultural theories, it excludes organisational variables other than sex ratio as well as personal characteristics of the harasser and the victim, which should also be considered in explaining the sexual harassment phenomenon (Joubert, 2009).

The four-factor theory (O'Hare \& O'Donohue, 1998) of sexual harassment includes key components of the single-factor theories discussed above. The four-factor theory offers one comprehensive model that can be used to explain a wide variety of sexually harassing behaviours (Jardim, 2004). The four-factor theory combines individual, organisational and socio-cultural factors (O'Hare \& O'Donohue, 1998). The fourfactor theory argues that, in order for sexual harassment to take place, four basic conditions must be present. Firstly, the individual must be motivated to harass (e.g. he or she must be driven by any combination of power, control or sexual attraction). Secondly, the individual must overcome internal inhibitions not to harass (e.g. viewing sexual harassment as illegal or immoral). Thirdly, the individual must overcome 
external inhibitions to harassment (e.g. explicit grievance procedures and consequences to harassers). Fourthly, the individual must overcome the victim's resistance (e.g. the victim's ability to recognise and stop predictive behaviour to harassment) (O'Hare \& O'Donohue, 1998; Pina et al., 2009).

Feminist perspectives aim to provide an understanding of the continued ways women are socially disadvantaged by men, by analysing the sexual oppression women suffer and by proposing interpersonal as well as social, political and legal solutions for gender equality (Lorber, 2010). 'Feminism refers to the belief that women and men should have equal opportunities in economic, political, and social life' (Barkan, 2012). Radical feminism blames patriarchy (male domination) for women's oppression (Barkan, 2012). Radical feminist theorists share the viewpoint that 'men [have] an interest in controlling women's reproduction and sexuality' (Bilton et al., 2002). They focus on how men exercise power over women at work and protect their own interests by intimidating women and excluding women from senior positions. Radical feminists believe that men use sexual harassment as a way to achieve such dominance (Haralambos \& Holborn, 2008).

From the above, it is evident that not one single theory or perspective can be singled out to explain the dimensions that may contribute to sexual harassment. The models discussed all attempt to provide some explanations for the occurrence of the sexual harassment phenomenon and hold some elements of truth, but are also subject to limitations. All factors discussed in each theory should be integrated to formulate a better understanding of the occurrence of the sexual harassment phenomenon in the workplace.

\section{Women in mining and sexual harassment}

It is evident from research conducted in various countries across the globe that women working in the core business of the mining sector are still viewed as sexual objects and are still subjected to sexual harassment of some kind. Main findings of some of the research are discussed below.

In Canada, research conducted at the International Nickel Company in the 1970s revealed that female mine workers were subjected to many forms of sexual harassment, such as sexual language, crude jokes, threats and verbal and physical assaults. The research indicated that men used sexual harassment to maintain masculine dominance in the workplace (Keck \& Powel, 2006). In the mid-1990s, Suzanne Tallichet investigated the world of women miners by spending several months in a West Virginia coal-mining community (Mercier, cited in Lahiri-Dutt, 2011). She found that women still faced tremendous challenges in the mining environment, including harassment from male co-workers and bosses and resistance from the community. Female miners endured discrimination, harassment and dangerous and demanding labour in order to gain access to mining jobs to enable them to provide and contribute towards more comfortable lives for their families. Recent studies, such as the Ramp-UP study, initiated by Women in Mining Canada, showed that women are still experiencing discrimination and sexual harassment in the mining industry (Women in Mining Canada, 2010).

In Australia in 1998, Pattenden (1998) was commissioned by the Australian Institution of Mining and Metallurgy's WIMnet (Women in Mining Network) to undertake indepth research on employment barriers inhibiting female participation in the industry. Pattenden's research focus was female technical professionals in fields such as geology, mine engineering and metallurgy. The researcher conducted 158 interviews with men and women working in the Australian minerals industry across numerous states, companies and commodity groups. The research revealed serious issues of harassment and discrimination (Pattenden, 1998).

In Papua New Guinea, Macintyre (cited in Lahiri-Dutt, 2011) conducted research on the experiences of women in the workplace over a period of 8 years, completing 100 surveys and 30 in-depth interviews. From the findings, it was evident that although most of the participants worked in government jobs, a significant group worked in the minerals industry. The research revealed, among other findings, that women face open antagonism, sexual harassment and discrimination in terms of opportunities for promotion, remuneration and inservice training when entering the workplace.

In South Africa, research conducted by various researchers and institutions revealed serious incidents of sexual harassment (Bench Marks Foundation, cited in Kolver, 2013; Botha, 2013; Fourie, 2009; MTS, 2011; Rawoot, 2014; The Guild, 2014). Sexual harassment incidents reported vary from whistling; name calling; use of vulgar or derogatory language; display of body parts; physical contact, ranging from touching to sexual assault and rape; to the exchange of sexual favours for a promotion, taking place on a daily basis. According to Shabangu (2012), former South African Minister of Mineral Resources, the number of reported incidents of women miners experiencing harassment and inhumane treatment by fellow workers in their underground workplaces is of particular concern. She emphasises that 'no woman should experience any sort of intimidation at the workplace that inhibit her to be the best and most productive employee she can be' (Shabangu, 2012, p. 4).

\section{Addressing sexual harassment in the mining industry}

In light of the above background, it is of paramount importance that mining companies follow the following steps to ensure a workplace free from sexual harassment (Nel et al., 2011; Noe, Hollenbeck, Gerhart \& Wright, 2008; Pons \& Deale, 2010):

- A good working sexual harassment policy must be developed. The policy statement must emphasise that sexual harassment in the workplace will not be tolerated.

- Training on the sexual harassment policy must be provided to all employees, old and new. 
- The policy should also explain the procedure that should be followed by employees who are victims of sexual harassment.

- A mechanism for reporting sexual harassment must be developed. Employees must be encouraged to speak out about and report these incidents.

- Sexual harassment complaints must be thoroughly investigated.

- Management must take prompt disciplinary action against those who commit sexual harassment and take appropriate action to protect the victims thereof.

The section to follow presents the research methodology that was employed for the research.

\section{Method}

The research methodology for this study stemmed from both positivism and phenomenology. A mixed-method research design was followed by applying a quantitative and qualitative research approach. Mixed-methods research is thought to enrich the quality of findings and their credibility, validity, generalisability and popularity, among others (Sarantakos, 2013).

\section{Research approach}

\section{Participants}

The research was conducted at the following three mines: a copper mine (underground), a platinum mine (underground) and a phosphate mine (open-cast). Convenience sampling was used to select the mines. Zikmund, Babin, Carr \& Griffin (2010) refer to convenience sampling as 'sampling by obtaining people or units that are conveniently available'.

Participants for the quantitative research were selected by employing convenience sampling. The study population consisted of the management of the three mines as well as male and female employees working in core mining activities. In total, responses were received from 156 research participants: 68 from the copper mine, 38 from the platinum mine and 50 from the phosphate mine.

Participants for the qualitative research were selected by using purposive or judgemental sampling. Purposive (judgemental) sampling is a non-probability sampling technique in which the units to be observed are selected on the basis of the researcher's judgement about which ones will be the most relevant to the project (Babbie \& Mouton, 2011). At all three mines, the human resource officer assigned to work with women in mining was responsible for selecting participants to be interviewed as well as scheduling the interviews. In total, 69 participants were interviewed in 12 individual interviews and 19 group interviews. The participants selected varied from various categories of employment (for e.g. managers, supervisors and general miners) and mining disciplines (for e.g. engineers, geologists and electricians).

\section{Measuring instruments}

Quantitative data were collected by means of a self-developed structured questionnaire consisting of open-ended and closed-ended questions. Further detail regarding the questionnaire construction is reported under the Analysis heading (below) and the Empirical findings section. Qualitative data were collected by means of individual and group interviews. Both the individual interviews and the group interviews were semi-structured. An interview guide was used to direct the conversations and to provide guidance to the interviews. Responses were audio recorded and written notes were taken.

Mixed-method research can enrich the quality and comprehensiveness of findings as well as their validity, generisability and popularity (Sarantokos, 2013). By combining the qualitative approach with the quantitative approach the researcher was able to gain better insight into the phenomenon of interest.

\section{Research process}

Firstly, permission was requested from mine management to conduct research at the three mining companies. After permission was granted, the researcher visited the research settings to explain the details of the research. At each mine, a contact person was assigned to the researcher to provide the necessary assistance and support during the research. These activities include, among others, distributing and collecting the questionnaires, selecting suitable participants for the interviews, scheduling interviews and organising relevant field trips (underground as well as at surface). Individual and group interviews were scheduled between shifts in order not to interfere with the work responsibilities of the participants. The following ethical practices were considered: voluntary participation, informed consent, privacy, anonymity and confidentiality (Babbie \& Mouton, 2011).

\section{Analysis}

Quantitative data obtained through the questionnaires were analysed by the statistical software program SPSS 21.0 for Windows. The frequency analysis is reported per statement as mean and the following ranking for scores was used: Not at all/Strongly disagree (1); Seldom/Disagree (2); Partially/ Agree (3) and Completely/Strongly agree (4). Ratings of 4 indicate that compliance with the specific statement is satisfactory, except for reversed statements. On the other hand, ratings of 2.5 and below show that compliance with the specific statement is none or very limited. The opposite is applicable for reversed statements; a statement with a mean above 2.5 could point towards a problem area.

Conceptual (thematic) analysis was used to analyse the responses obtained through the individual and group interviews. The following coding steps suggested by Palmquist (cited in Babbie \& Mouton, 2011) were used: deciding on the level of analysis, deciding on how many concepts to code for, 
deciding whether to code for the existence or frequency of a concept, deciding how to distinguish between concepts, developing rules for the coding of texts, deciding what to do with the data that are irrelevant, coding the data and analysing the results.

\section{Strategies employed to ensure the validity and reliability of data}

Reliability relates to the findings of the research and the credibility of the findings. Furthermore, reliability refers to the extent to which the obtained scores may be generalised to different measuring occasions, measurement or test forms and measurement or test administrators (Welman, Kruger \& Mitchell, 2010). Validity refers to the extent to which the research findings accurately represent what is really happening in the situation. It means that an effect or test is valid if it demonstrates or measures what the researcher thinks or claims it does (Coolican, cited in Welman et al., 2010).

Triangulation, the use of multiple methods, is considered as one of the best ways to enhance the validity and reliability of research. Triangulation can take place according to paradigms, methodologies, methods, researchers and so forth (Babbie \& Mouton, 2011). This research was triangulated by means of the following: A literature study and empirical review were conducted, the quantitative as well as qualitative research paradigms were used and various data collection methods were used. Quantitative data were collected through questionnaires, while qualitative data were collected by means of group discussions, semi-structured interviews as well as observations. Male and female employees in management positions as well as male and female employees working in the core business of mining were interviewed to obtain different perspectives on various issues that have an impact on women working in the core business of mining. The researcher also visited the different research settings (mines) and experienced the underground environment while spending some time with women working underground. She also visited the smelter, the concentrator and the refinery and spent some time with women working in core activities on the surface. In addition, Women in Mining conferences were interviewed in order to broaden and deepen the researcher's insight into the variables that have an impact on women working in the core business of mining.

\section{Findings}

The section to follow presents the quantitative and qualitative findings of the participants' opinions regarding sexual harassment in the workplace.

\section{Sexual harassment policy}

Questions were included in the survey to determine whether the participants are fully aware of the sexual harassment policy provided by the mining companies (see Table 1), to establish whether women working in core mining activities have sufficient knowledge of the content and operational procedures of the sexual harassment policy (see Table 2), to verify whether the policy is adequate (see Table 2) and to

TABLE 1: Participants' awareness of the sexual harassment policy.

\begin{tabular}{|c|c|c|c|c|c|c|}
\hline \multirow[t]{2}{*}{ Mine } & \multicolumn{2}{|c|}{ Male target group } & \multicolumn{2}{|c|}{ Female target group } & \multicolumn{2}{|c|}{ Management target group } \\
\hline & $F$ & $N$ & $F$ & $N$ & $F$ & $N$ \\
\hline Copper mine & 16 & 17 & 29 & 34 & 16 & 17 \\
\hline Phosphate mine & 12 & 17 & 20 & 21 & 11 & 12 \\
\hline Platinum mine & 16 & 16 & 19 & 22 & - & - \\
\hline
\end{tabular}

Source: Botha, D. (2013). Women in mining: A conceptual framework for gender issues in the South African mining sector. Unpublished PhD dissertation, North-West University, Potchefstroom

TABLE 2: Participants' perceptions regarding mining companies' sexual harassment policies.

\begin{tabular}{|c|c|c|c|c|c|c|c|c|c|}
\hline \multirow[t]{2}{*}{ Question } & \multicolumn{3}{|c|}{ Male target group } & \multicolumn{3}{|c|}{ Female target group } & \multicolumn{3}{|c|}{ Management target group } \\
\hline & $\begin{array}{l}\text { Seldom to not } \\
\text { at all }\end{array}$ & $\begin{array}{l}\text { Partially to } \\
\text { completely }\end{array}$ & Mean & $\begin{array}{l}\text { Seldom to not } \\
\text { at all }\end{array}$ & $\begin{array}{l}\text { Partially to } \\
\text { completely }\end{array}$ & Mean & $\begin{array}{l}\text { Seldom to not } \\
\text { at all }\end{array}$ & $\begin{array}{l}\text { Partially to } \\
\text { completely }\end{array}$ & Mean \\
\hline \multicolumn{10}{|l|}{ Copper mine } \\
\hline $\begin{array}{l}\text { 1.Do you feel women working in core mining } \\
\text { activities have sufficient knowledge of the } \\
\text { content and operational procedures of the } \\
\text { sexual harassment policy? }\end{array}$ & 0.0 & 100.0 & 3.7 & 13.4 & 86.6 & 3.4 & 0.0 & 100 & 3.9 \\
\hline $\begin{array}{l}\text { 2.Do you think the mining company's policies } \\
\text { work well? }\end{array}$ & 5.9 & 94.1 & 3.6 & 10.0 & 90.0 & 3.3 & 0.0 & 100 & 3.7 \\
\hline \multicolumn{10}{|l|}{ Phosphate mine } \\
\hline $\begin{array}{l}\text { 1.Do you feel women working in core mining } \\
\text { activities have sufficient knowledge of the } \\
\text { content and operational procedures of the } \\
\text { sexual harassment policy? }\end{array}$ & 12.5 & 87.5 & 3.5 & 21.1 & 79.0 & 3.4 & 0.0 & 100.0 & 3.6 \\
\hline $\begin{array}{l}\text { 2.Do you think the mining company's policies } \\
\text { work well? }\end{array}$ & 18.8 & 81.2 & 3.6 & 23.8 & 76.2 & 3.3 & 0.0 & 100.0 & 3.8 \\
\hline \multicolumn{10}{|l|}{ Platinum mine } \\
\hline $\begin{array}{l}\text { 2.Do you think the mining company's policies } \\
\text { work well? }\end{array}$ & 7.7 & 92.3 & 3.5 & 10.6 & 89.4 & 3.4 & - & - & - \\
\hline
\end{tabular}

Source: Botha, D. (2013). Women in mining: A conceptual framework for gender issues in the South African mining sector. Unpublished PhD dissertation, North-West University, Potchefstroom 
determine gaps in the policy provided (see qualitative findings). The findings are presented differentially in terms of the three mines (see Tables 1, 2 and 3).

The results in Table 1 show that almost all participants across the three mines are aware of the existence of the sexual harassment policy.

From the results in Table 2, it is evident that a vast majority of the participants (male, female and management target groups) across all three mines hold the opinion that women working in core mining activities have sufficient knowledge of the content and operational procedures of the sexual harassment policy. The mean scores for almost all the target groups across the three mines calculated above 3 .

Although the quantitative findings revealed relatively positive results, the qualitative enquiry (semi-structured interviews and open-ended questions of the questionnaire) revealed loopholes as well as limitations regarding the

TABLE 3: Participants' perceptions regarding sexual harassment and sexual favouritism in the workplace.

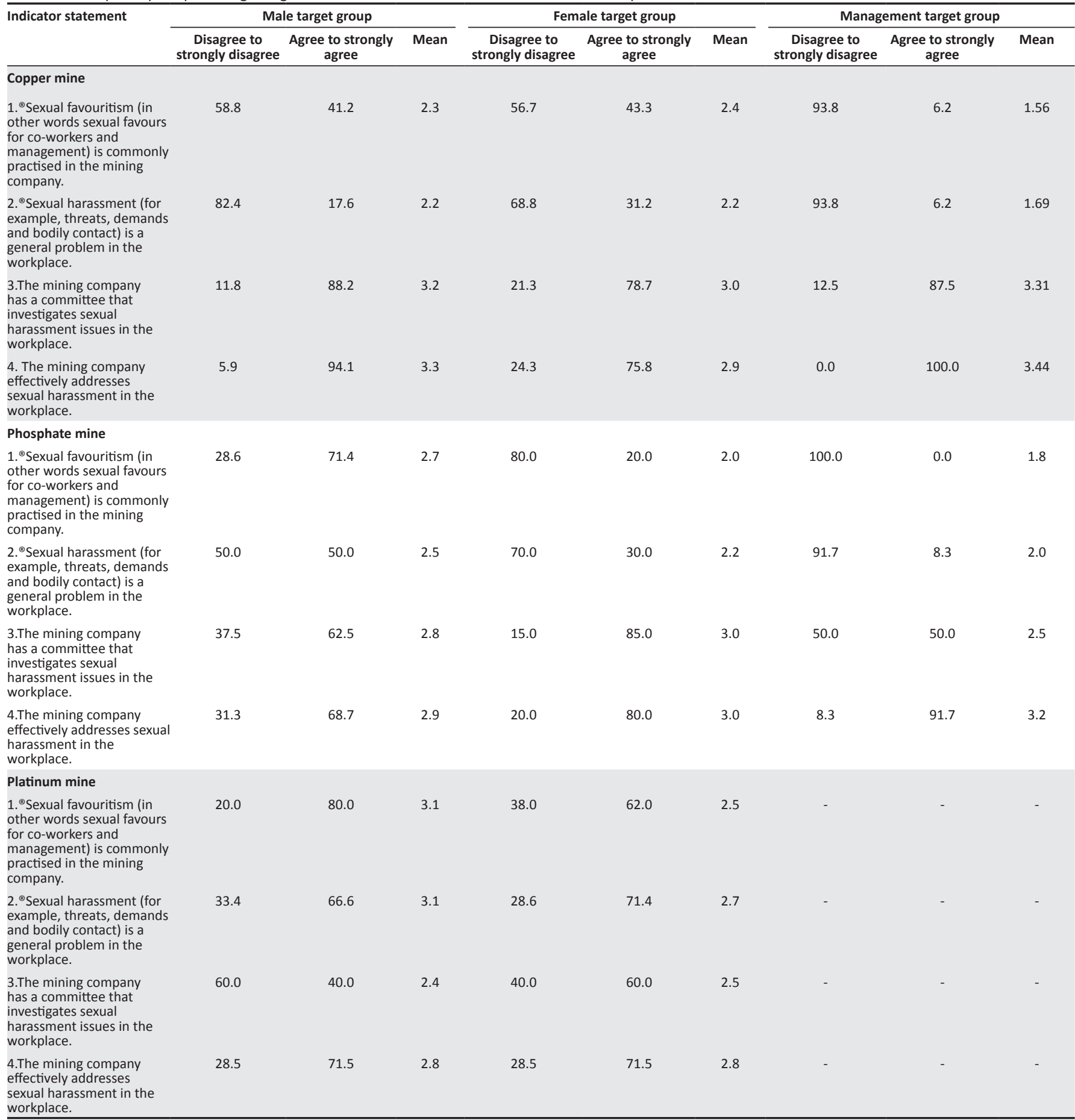

Source: Botha, D. (2013). Women in mining: A conceptual framework for gender issues in the South African mining sector. Unpublished PhD dissertation, North-West University, Potchefstroom

, Reversed statement - statement formulated in the opposite direction. 
sexual harassment policy. The main concerns identified were discussed in the subsequent sections.

\section{Lack of knowledge}

Although the quantitative findings revealed that the female participants working in the core business of mining demonstrate partial to complete knowledge of the content and operational procedures of the sexual harassment policies, a serious need for workshops and continuous training on policies was detected. This statement is reinforced by the following quotations:

We don't have much knowledge of the policies, because we are just operators. We just see things in a distance, we are not close to it, and we do not really know what is happening. (Female, operator, copper mine)

I think each policy should be discussed at least once to get a good understanding of it. (Female, mining engineer, copper mine)

\section{Lack of transparency}

A need for transparency was strongly voiced. The participants indicated that policy documents should be available to each and every employee of the mines. The following comment was made by a participant in this regard:

The mine is self-centred when [it comes] to some or the majority of the outspoken policies. Mine does not do enough for the information to reach employees. There is a loophole between management and employees. (Male, safety officer, platinum mine)

\section{Gaps between policies and policy implementation}

Although the intention of specific company policies is to coordinate and regulate particular aspects of the employment relationship, a gap often exists between policies and the implementation thereof. Although policies exist, problems are experienced with the actual implementation and application thereof. The following quotation provides an indication of one of the participants' opinions regarding the implementation and application of policies:

A lot of things looks good on paper, but the application thereof is quite a different thing. (Female, fitter and turner, copper mine)

\section{The occurrence of sexual harassment and sexual favouritism in the workplace}

Questions were included in the survey to determine whether the female participants had been approached for sex in the workplace in exchange for favours and whether they have ever been sexually harassed in the workplace. The responses to these questions were extremely positive across the mines, as only an insignificant percentage answered 'yes', as indicated in Figures 1 and 2.

Although the quantitative responses revealed only positive results, the literature review as well as the qualitative enquiry indicates that sexual harassment and sexual favouritism remain major issues in the mining industry. Detailed concerns regarding sexual harassment are reported further on in this section.
The statements in Table 3 aimed to determine the perceptions regarding sexual harassment and sexual favouritism within the mining companies included in the study.

From Table 3, it is evident that the majority of the participants (all target groups) of the copper mine positively indicated that sexual favouritism is not commonly practised in the mining companies and that sexual harassment is not regarded as a general problem in the workplace. This view was supported by the majority of the participants of the female and management target groups of the phosphate mine, but not by the male target group. Positive responses calculated a mean below 2.5 and because these statements are reversed, it does not point towards a problem area. A distressing observation is that a vast majority of the male participants of the phosphate mine (sexual favouritism: 71.4\%; sexual harassment: $50 \%$ ) and the male (sexual favouritism: $80 \%$; sexual harassment: $66.6 \%$ ) and female (sexual favouritism: $62 \%$; sexual harassment: $71.4 \%$ ) participants of the platinum mine reported that sexual favouritism and sexual harassment are general problems in the workplace; these (reversed) statements calculated a mean of 2.5 and above.

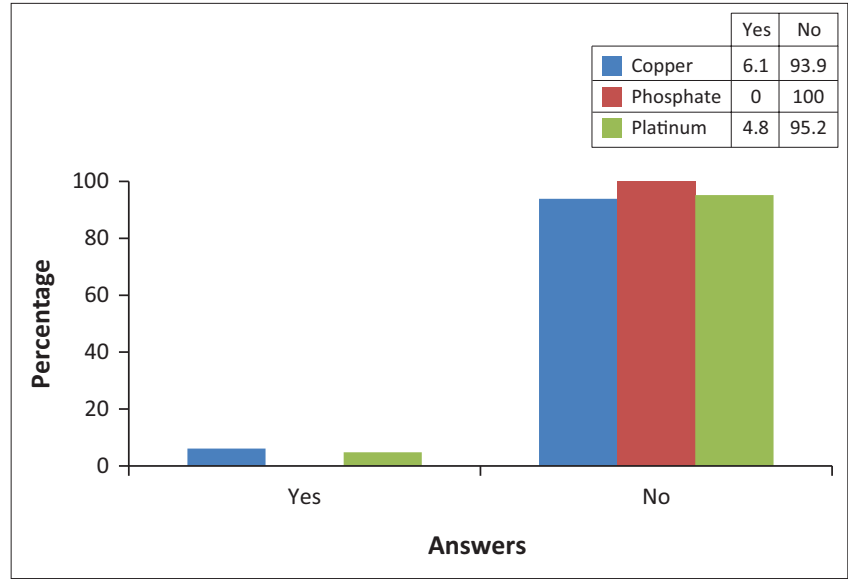

Source: Botha, D. (2013). Women in mining: A conceptual framework for gender issues in the South African mining sector. Unpublished PhD dissertation, North-West University, Potchefstroom

FIGURE 1: Have you ever been approached for sex in the workplace in exchange for favours?

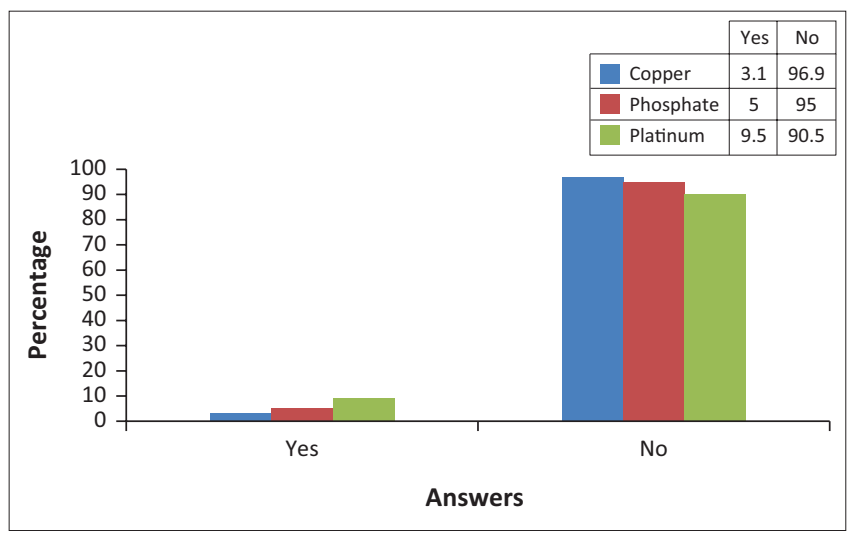

Source: Botha, D. (2013). Women in mining: A conceptual framework for gender issues in the South African mining sector. Unpublished PhD dissertation, North-West University, Potchefstroom

FIGURE 2: Have you ever been sexually harassed in the workplace? 
Different views were obtained for the indicator The mining company has a committee that investigates sexual harassment issues in the workplace. A vast majority of the participants (all target groups) of the copper mine reacted positively to this indicator. More than $60 \%$ of the male and female participants of the phosphate mine supported this opinion, while a split opinion was obtained from the majority of the management participants. The responses from the copper and phosphate mines were positive in the sense that on average, the participants are aware of committees that investigate sexual harassment issues in the mining companies. Furthermore, a vast majority of the participants of the copper and phosphate mines (more than 68\%) agreed to strongly agreed that The mining company effectively addresses sexual harassment in the workplace. It can therefore be assumed that employees of the copper and phosphate mines are satisfied with the way sexual harassment is addressed in the companies. However, this view was not supported by the male and female participants of the platinum mine. Although it was indicated by the majority of the participants of the platinum mine that The mining company effectively addresses sexual harassment in the workplace (male and female participants: $71.4 \%$ ), a slight majority of the female participants $(60 \%)$ and only $40 \%$ of the male participants reported that The mining company has a committee that investigates sexual harassment issues in the workplace. The mean calculated at 2.4, indicating that compliance with this statement is very limited. The platinum mining company needs to establish a committee if one does not exist or create awareness if there is in fact such a committee.

It was evident from the qualitative inquiry that the participants of all three mines included in the study confirmed that sexual harassment is seen as a serious offence and that training and education take place regularly at the mines. Furthermore, companies engage in the practices of training sessions for newly recruited employees and regular awareness campaigns on the procedures to follow if sexual harassment occurs. Despite these attempts, sexual harassment remains an issue and incidents do occur. The main concerns regarding sexual harassment were raised during the individual and group interviews, discussed in the subsequent sections.

\section{Afraid to report sexual harassment attempts}

Although the majority of the female participants indicated that they are familiar with the procedure to follow if sexually harassed, there are still women who are unsure of their rights and who are still afraid of reporting sexual harassment attempts or incidents. The following reasons were put forward for why women often remain silent: They are afraid of losing their jobs at the mine, they do not want to put their male co-workers in a 'bad' position and they do not find it easy to lodge complaints of harassment with male supervisors.

\section{Verbal sexual harassment}

It was indicated that women are exposed to verbal sexual harassment on a regular basis, especially when they are being transported in packed cages. Moreover, because of the nature of the mining industry as a male-dominated workplace, men are used to communicating in certain ways and often use 'bad language' when carrying out heavy tasks. Female co-workers often feel offended by the way men communicate and by the type of language they use. The following quotations illustrate these points:

Verbal sexual harassment happens almost every day. (Female, operator, copper mine)

Men often called me 'baby' or 'sweetheart'. They feel that they can call me anything. (Female, electrician, copper mine)

Some men can make you feel so small, like maybe you are in the cage, they call you names. Some tell you that 'you are fat, you are wasting our time, let me pass'. So not all men are accepting that women are working on the mine. Some things that they say, they think they are funny and you can see that this person doesn't know he can lose his job. They think sexual harassment is just touching a person, they don't know if you insult a person it is sexual harassment, so they have still a lot to learn. (Female, learner rock breaker, platinum mine)

\section{Night shift}

It was reported that working the night shift contributes to the occurrence of sexual harassment incidents, as male coworkers often take advantage of these circumstances. Women do not feel at ease and safe when working with so many men during the night:

To be honest, we are sexually harassed. They take advantage of us, because we are women and we are working at night with them. It is very uncomfortable. Let me just stop right there, because it is very uncomfortable. But what can you do, because it is a small place. (Female, operator, copper mine)

\section{Packed cages}

It became clear that the cages in which workers are transported are normally packed to maximum capacity and therefore also contribute to the occurrence of sexual harassment incidents. Physical contact is inevitable; employees are obliged to press against each other. The following comments were made in this regard:

In the cage, they will push us like this and you can't even breathe and the man is after you, you can feel his whole body pressing against you. Then they say like 'what are you doing here at the mine?', 'my woman is at home, you are here at the mine'. (Female, general worker, platinum mine)

There are too many people in the cage. The big one takes 80 people down, 80 people up. The small one takes 35 people. But these girls who are working there, they don't count, they can put maybe 100 into the cage. Some men take advantage and push against the ladies. (Male, development crew, platinum mine)

\section{Sexual favouritism}

Although discrepancies were evident in the quantitative results (see Table 3), it was clearly indicated in the group discussions as well as the interviews that sexual favouritism occurs at the mines. The male participants of the platinum mine were outspoken and indicated that some female co-workers 'fall in love' with their supervisors to easily 
get promotions. It was also suggested that the problem is exacerbated by shift work and working overtime at night. This contributes towards the negative attitude from male employees towards women employed in core mining positions. The female participants, although not so outspoken, indicated that they are aware of sexual favouritism incidents. The following quotations provide an indication of the participants' opinions regarding the occurrence of sexual favouritism at the mines included in the study:

Ja, it does happen. Like they won't do it where everybody is looking, but you see that something is going on here and that person will be favoured. But all the promotions that person will get because you know that she did 1,2,3 ... And it is not nice for other women who are working with that lady, because you know you are not going anywhere because you don't want to sleep with that guy. (Female, learner rock breaker, platinum mine)

For them it is easy to get promotion, because they fall in love with the official and they get promotion. I've been working 10 years, but no promotion. (Male, teamleader, platinum mine)

\section{Male participants' response}

According to the male participants, women often misuse sexual harassment to manipulate men in the workplace, as noted in the following comment:

Some women have this attitude. I'm working, nobody can touch me, nobody can do me nothing. You touch her, you harass her. If she doesn't like you, you harass her. Slight mistake, you're gone in mining. And the company is going to follow the procedure of the mine. Even the woman can touch me, I can't say the woman has harassed me. Let me touch her, I've harassed her. (Male, electrical assistant, platinum mine)

\section{Management's response}

It was evident from the qualitative inquiry that sexual harassment is regarded as a serious offence and is also treated accordingly. Management of the different mining companies aim to minimise the occurrence of sexual harassment by conducting regular training and education interventions on sexual harassment. The following comment was made in this regard:

Some form of harassment will always be part of the workplace, but we as management will not tolerate any sexual harassment. If management do not act decisively against it, you will never really get rid of it. It also depends on the behaviour of the woman. She must also act decisively, in other words if it looks like the guys want to tell dirty jokes, she must say 'no' beforehand. But I also feel that if you want to work in the mining industry, you should not be faint-hearted. Sometimes men use bad language when they are struggling doing a job. They do not mean to talk badly. (Female, senior manager, phosphate mine)

\section{Discussion}

\section{Outline of the findings}

From the research (literature review, quantitative results and qualitative findings) it is evident that sexual harassment and sexual favouritism remain serious concerns in the mining industry. Although sexual harassment is treated as a serious offence by management (of the three mines included in the study) and is not tolerated, sexual harassment incidents take place on a daily basis and in varied forms. It is clear that some mines are faring better than others with regard to the handling of sexual harassment and sexual favouritism in the workplace.

The quantitative results suggest that a vast majority of the participants, across all three mines, are aware of the existence of the sexual harassment policy, demonstrate sufficient knowledge of the policy and hold the opinion that the policy is working well. However, the qualitative findings showed that there are still employees who lack knowledge of the content and operational procedure of the policy; a need for transparency was indicated. Furthermore, it was also indicated that, although policies exist, problems are experienced with the actual implementation and application thereof. As indicated in the literature review, regular training for old and new employees on the sexual harassment policy is of utmost importance. Furthermore, mining companies should also have a business plan in place to facilitate the implementation of the policy (Nel, Kirsten, Swanepoel, Erasmus \& Poisat, 2012).

Although Figures 1 and 2 reveal only positive responses with regard to the questions: Have you ever been approached for sex in the workplace in exchange for favours? and Have you ever been sexually harassed in the workplace?, the results in Table 3 show that on average, the female and male participants of the platinum mine as well as the male participants of the phosphate mine agreed that these practices are common in the workplace. The qualitative inquiry also revealed serious concerns in this regard. It is evident that verbal and physical forms of harassment are still regular occurrences in the mining workplace, as also indicated in the literature review. Packed cages and working the night shift are blamed for exacerbating the problem. The findings are also in line with research conducted by Benya (2009), Botha (2013), MTS (2011), Scheepers (2013), The Guild (2014) and Women in Mining South Africa (WiMSA, 2015). Recent research conducted by WiMSA (2015) revealed that the exchange of sexual favours to achieve advantages is an unfortunate reality in the mining industry. Furthermore, the research indicated that reporting systems are not working as they should and a need was voiced for anonymous reporting systems, considerably more management commitment and visible leadership, more women in the labour force (also in management positions) and an independent oversight mechanism.

\section{Recommendations}

In the light of the findings of the research, the following recommendations are made:

- Management should show more visible leadership and ongoing commitment in terms of sexual harassment. Implementation and operationalisation of the sexual harassment policy as well as relevant mechanisms are required. The content of the policy should be 
communicated to all employees (male and female employees) on a regular basis via training and workshops. A clear reporting mechanism should be developed. Anonymous reporting lines are suggested to protect victims. Prompt action on sexual harassment incidents is fundamental.

- An effective support system (Women in Mining Forum, female representatives at shafts, etc.) for women in mining should be implemented. Issues raised should be addressed effectively and speedily. Measures such as career counselling should be provided to support women in dealing with sexual harassment issues in the workplace.

- Management should consider appointing more than one woman in a work team to prevent isolation and to make the work environment more conducive to women.

- Companies should engage in regular research interventions to measure progress on sexual harassment incidents and to reveal further issues in this regard.

\section{Practical implications}

Although mining companies view sexual harassment as a serious offence and treat it accordingly, it is evident that much more needs to be done to minimise and eliminate the occurrences of sexual harassment in the workplace. A holistic approach, which requires input of relevant state departments such as the Department of Mineral Resources and the Mine Health and Safety Council, regular training and awareness campaigns on sexual harassment and prompt action by human resource managers and labour experts, is needed. Relevant state departments (mentioned above) should be outspoken on the topic and should engage in regular research interventions to measure the status of sexual harassment in the mining industry. They should show visible leadership by assisting mining companies to eradicate sexual harassment in the industry. Human resource managers and labour experts should not only develop and implement a sexual harassment policy but also implement prompt disciplinary action.

\section{Limitations of the study}

A limitation of the study lies in the accessibility of the mining sector as a research setting. To gain access to the mines was extremely difficult. A number of correspondences took place before permission was granted for the research. The platinum mine also experienced many difficulties and labour unrest during the time the research was conducted. This eventually culminated into the postponement and cancelling of interviews as well as no quantitative responses (questionnaires) from the management target group. The following additional factors also posed challenges to the research: not all participants scheduled for the interviews turned up for the meetings and others could not stay for the duration of the interviews due to work responsibilities, emergencies and tiredness as a result of shift work.

\section{Conclusion}

From the research, it is clear that women working in the core business of the mining industry are still exploited and sexually harassed. Employment relations practitioners and labour experts should take note of the seriousness of this phenomenon. All necessary measures should be taken to prevent and address sexual harassment complaints and incidents.

\section{Acknowledgements Competing interests}

The author declares that she has no financial or personal relationships that may have inappropriately influenced her in writing this article.

\section{References}

Anderson, M.L., \& Taylor, H.F. (2006). Sociology: Understanding a diverse society. Belmont, MA: Thomson Learning.

Babbie, E., \& Mouton, J. (2011). The practice of social research. Cape Town: Oxford University Press Southern Africa.

Badenhorst, C.J. (2009). Occupational health and safety considerations for the employment of female workers in hard rock mines. Paper presented at the Southern African Institute of Mining and Metallurgy, Hard Rock Safety Conference, 28-30 September, Sun City, South Africa.

Barkan, S.E. (2012). A primer on social problems. Retrieved June 17, 2016, from http://2012books.lardbucket.org/pdfs/a-primer-on-social-problems.pdf

Benya, A.P. (2009). Women in mining: A challenge to occupational culture in mines. Unpublished MA dissertation, University of the Witwatersrand, Johannesburg.

Bilton, T., Bonnett, K., Jones, P., Lawson, T., Skinner, D., Stanworth, M., \& Webster, A. (2002). Introductory sociology. (4th edn.). New York: Palgrave Macmillan.

Botha, D. (2013). Women in mining: A conceptual framework for gender issues in the South African mining sector. Unpublished PhD dissertation, North-West University, Potchefstroom.

Fourie, J.D. (2009). Managerial challenges faced in a South African platinum mine relating to women employment as required by the Mining Charter. Unpublished MBA mini-dissertation, North-West University, Potchefstroom.

Grobler, P.A., Wärnich, S., Carrell, M.R., Elbert, N.F., \& Hatfield, R.D. (2011). Human resource management in South Africa. (4th edn.). London: Cengage Learning EMEA.

Hakim, C. (2004). Key issues in women's work: Female diversity and the polarisation of women's employment. (2nd edn.). London: Glasshouse Press.

Haralambos, M., \& Holborn, M. (2008). Sociology: Themes and perspectives. (7th edn.). London: HarperCollins.

Harmony Gold Mining Company. (2008). Harmony sustainable development report. Retrieved October 20, 2009, from http://www.har.co.za/files/Harmony_SD2008. pdf

Jardim, L. (2004). The management of sexual harassment in the workplace. Unpublished PhD dissertation, North-West University, Potchefstroom.

Joubert, P.A. (2009). Sexual harassment of academic staff at higher education institutions in South Africa. Unpublished PhD dissertation, North-West University, Potchefstroom.

Keck, J., \& Powel, M. (2006). Women into mining jobs at Inco: Challenging the gender division of labor. In J.J. Gier \& L. Mercier (Eds.), Gender in the development of a global industry, 1670 to the present (pp. 280-295). New York: Palgrave Macmillan.

Kolver, L. (2013). Women still being hassled in male-dominated mining environment Retrieved August 14, 2015, from http://www.miningweekly.com/article/femalemineworkers-still-being-exploited-sexually-harassed-bench-marksfoundation-2013-05-10

Lahiri-Dutt, K. (2011). Gendering the field: Towards sustainable livelihoods for mining communities. Retrieved February 25, 2012, from http://epress.anu.edu. au/gendering_field_citation

Managing Transformation Solutions. (2011). Second Annual Women in Mining Conference. Unpublished report, 23-25 February.

Mcdonald, P. (2012). Workplace sexual harassment 30 years on: A review of the literature. Retrieved May 15, 2016, from http://onlinelibrary.wiley.com/ doi/10.1111/j.1468-2370.2011.00300.x/abstract;jsessionid=BB62B975F0A82800 9D54DDD759BD74CF.f04t04?userlsAuthenticated=false\&deniedAccessCustomis edMessage $=$

Mining Safety. (2013). Are we doing enough for the safety of female miners? Retrieved from http://www.miningsafety.co.za/dynamiccontent/124/Are-we-doing-enoughfor-the-safety-of-female-miners

Nel, P.S., Kirsten, M., Swanepoel, B.J., Erasmus, B.J., \& Poisat, P. (2012). South African employment relations: Theory and practice. (7th edn.). Pretoria: Van Schaik.

Nel, P.S., Werner, A., Poisat, P., Sono, T., Du Plessis, A., \& Ngalo, O. (2011). Human resources management. (8th edn.). Cape Town: Oxford University Press Southern Africa. 
Noe, R.A., Hollenbeck, J.R., Gerhart, B., \& Wright, P.M. (2008). Human resource management: Gaining a competitive advantage. (8th edn.). New York: McGraw-Hill.

O'Hare, E.A., \& O'Donohue, W. (1998). Sexual harassment: Identifying risk factors. Archives of Sexual Behaviour, 27, 561-580. http://dx.doi.org/10.1023/ A:1018769016832

Pattenden, C. (1998). Women in mining: A report to the "Women in Mining" Taskforce The Australasian Institute of Mining and Metallurgy. Retrieved February 25, 2012, from https://www.ausimm.com.au/content/docs/wimreport.pdf

Pina, A., Gannon, T.A., \& Saunders, B. (2009). An overview of the literature on sexual harassment: Perpetrator, theory, and treatment issues. Retrieved May 15, 2016 from http://www.sciencedirect.com/science/article/pii/S1359178909000044

Pons, A., \& Deale, P. (2010). Labour relations handbook (revision service 18). Cape Town: Juta.

Rawoot, I. (2014). Mining while female: The perils of Marikana. Retrieved August 14 2015, from http://www.aljazeera.com/indepth/features/2014/01/mining-whilefemale-perils-marikana-20141582421339881.html

Republic of South Africa. (2002). Mineral and Petroleum Resources Development Act, No. 28 of 2002. Pretoria: Government Printers.

Republic of South Africa. (2004, August 13). Broad-based Socio-economic Empowerment Charter for the South African Mining Industry. Notice No. 1639 of 2004. Government Gazette, 25899, 6-17.

Sarantakos, S. (2013). Social research. (4th edn.). New York: Palgrave Macmillan.

Scheepers, A. (2013). Overcoming the challenge of occupational culture at the mines. Unpublished MBA thesis, Stellenbosch University, Stellenbosch.
Shabangu, S. (2012, October 26). Address by the South African Minister of Mineral Resources, Susan Shabangu (MP), at the Women in Mining and Development leadership forum, Sandton. Retrieved May 07, 2013, from http://www.dmr.gov. za/publications/viewdownload/198-minister-speeches-2012/881-address-byza/publications/viewdownload/198-minister-speeches-2012/881-address-bythe-south-african-minister-of-mineral-resources-ms-susan-shabangu-mp-at-
the-women-in-mining-and-development-leadership-forum-26-october-2012. html

Slabbert, Y. (1994). Sexual harassment in the workplace. Unpublished master's dissertation, University of Cape Town, Cape Town.

Tangri, S., Burt, R., \& Johnson, B. (1982). Sexual harassment at work: Three explanatory models. Journal of Social Issues, 38(4), 33-54. http://dx.doi.org/10.1111/j.15404560.1982.tb01909.x

The Guild. (2014). Sexual harassment against women in mines. Unpublished report.

Welman, C., Kruger, F., \& Mitchell, B. (2010). Research methodology. (3rd edn.). Cape Town: Oxford University Press Southern Africa.

Wharton, A.S. (2006). The sociology of gender: An introduction to theory and research Oxford: Blackwell.

Women in Mining Canada. (2010). Ramp-UP: A study on the status of women in Canada's mining and exploration sector. Retrieved from http://www.0101.nccdn. net/1_5/1f2/13b/0cb/RAMP-UP-Report.pdf

Women in Mining South Africa. (2015). WiMSA survey results 2015. Unpublished report.

Zikmund, W.G., Babin, B.J., Carr, J.C., \& Griffin, M. (2010). Business research methods. (8th edn.). Australia: South-Western Cengage Learning. 